\title{
The impact of creative learning environments on learners: a systematic literature review
}

Divya Jindal-Snape, Professor, University of Dundee, UK

and

Dan Davies, Professor, University of Bath Spa, UK

\begin{abstract}
This paper is based on a systematic review of educational research, policy and professional literature relating to creative environments for learning in schools. Despite the search yielding 210 documents, comparatively few empirical studies were published between 2005 and 2011 that addressed the review objectives. Only 18 studies included in the review investigated the impact of creativity on learners. There was, however some evidence for the impact of creative learning environments on pupil attainment, confidence, resilience, motivation, problem-solving, interpersonal skills and school attendance. These findings have implications for policy, practice and research internationally.
\end{abstract}

Keywords: Creativity, Learners, Resilience, Motivation, Engagement, Achievement

\section{Introduction}

Are some learning environments more conducive to promoting creativity in children and young people than others? By 'learning environment' we mean much more than the physical architecture of the space in which learning takes place (Dude 2000); our definition encompasses both psychosocial and pedagogical features of such environments (Fraser \& Fisher 1982; Roth 2000). Equally, our definition of creativity embraces creative thought processes (Mumford et al. 1991), creative problem-solving skills (Williamson 2011), creative 
thinking (Torrance 1977), creative learning (Jeffrey 2006) and possibility thinking (Craft 2001, 2010). Whilst such creative behaviours and dispositions may be associated with certain types of learning environment, there may be other benefits for learners - both cognitive and social - gained through participation in an environment which promotes creativity (see Box $1)$.

This was one of the areas for exploration from published empirical literature which the curriculum agency of the Scottish government - Learning and Teaching Scotland (LTS) (now Education Scotland) - commissioned the authors to review in 2011.

LTS's overall aim was to review evidence identifying the most effective learning environments and conditions which promote creative skills development in children and young people, whilst the objectives of the review were:

1. To describe the key characteristics of the environments and conditions that are most effective in promoting creative skills development in children and young people.

2. To describe the impact of creative school learning environments on the educational development of children and young people.

3. To describe the roles of teachers in promoting creative skills development in pupils.

4. To describe how teachers can best be supported to develop the skills and confidence to facilitate creative learning environments.

This article focuses upon the second objective above, so reports on the evidence in the literature related to the impact of creative school learning environments on the educational development of children and young people, taking into account gender and cultural or socioeconomic contexts

\section{Methodology}

The research team derived the following research questions from the above objectives:

RQ1. What evidence in the literature is there for identifying key characteristics of the environments and conditions that are most effective in promoting creative skills development in children and young people? 
RQ2. What evidence in the literature is there for impact of creative school learning environments on the educational development of children and young people, taking into account gender and cultural or socio-economic contexts?

RQ3. What evidence in the literature is there for identifying specific roles of teachers which promote creative skills development in pupils?

RQ4. What evidence in the literature is there for ways in which teachers can best be supported to develop the skills and confidence to facilitate creative learning environments?

We undertook a systematic literature review following the EPPI-centre (2007) methodology, comprising the following stages:

1. Scoping the review

2. Searching for studies

3. Screening studies

4. Describing and mapping

5. Quality and relevance appraisal

6. Synthesising study findings

7. Conclusions/recommendations

Full details of the above methodology are available in Davies et al. (2012). The research team comprised six researchers, enabling triangulation for quality assurance and verification of interpretation at all seven stages. We started by developing explicit inclusion and exclusion criteria for specifying which literature would be included in the review; these included issues concerning topic, recency, age-range, geographical spread, research base, transparency and validity. We then searched for studies using a series of terms related to creativity and innovation, agreed with LTS. Different members of the team searched journal articles, books, government websites, grey literature and Google Scholar, before pooling the findings and meeting to screen the studies jointly against the inclusion criteria. We outlined the methodology and findings from each included study, including variables such as population focus, study design and key characteristics related to the research questions. These were used to draw up a 'descriptive map' providing a systematic description of each study in relation to each research question. Finally, we used the approach of Narrative Empirical Synthesis 
(EPPI-Centre 2007) to bring together the results of the mapping exercise to provide an accessible combination of results from individual studies in structured summaries.

\section{Results}

This paper focuses upon findings related to Research Question 2 (RQ2) above. For findings against RQ1 please see Davies et al (2012). 210 publications were considered for inclusion in relation to this question, of which 18 were deemed to meet criteria for inclusion and contained findings relating to impact on learners. Of these, only three studies made mention of gender or socio-economic contexts. However, there were also four additional studies which referred to impact on staff - teachers or student teachers. The reported impacts on children and young people relate to their academic achievement; increased confidence and resilience; enhanced motivation and engagement; development of social, emotional and thinking skills; and improved school attendance. Each of these impacts will be considered in turn below. However, before moving to the impact, let's look at what environments and activities were seen to promote creativity across different countries (see Davies et al. 2011 for details) (see Box 1).

HMIE in Scotland summarised what 'good practice' was evident in different settings across Scotland. This summary will give readers an insightful overview into what is happening within the context of one country (see Box 2).

Similarly, Ofsted (2010) identified the following characteristics of effective creative teaching on the basis of inspection in 44 schools in England (see Box 3).

Keeping these examples of good practice and types of work undertaken in schools, let us consider the impact of such work on learners. 


\section{Impact on learners}

\section{Achievement}

Perhaps surprisingly, given the difficulty of establishing causality between external factors and pupil achievement, the greatest weight of evidence in the literature reviewed related to reported impacts on pupils' academic attainment from immersion in creative environments. In their review of 19 case studies of creative learning from Scottish schools, LTS (2004) reported that one of the main outcomes for students was a sense of personal success. Schacter et al.(2006), reporting on an observational study of 48 primary teachers working with 816 pupils in US schools over a year, concluded that creative teaching substantially improves student achievement. The pupils in their study taught by teachers who regularly elicited their creativity made much larger achievement gains than those in less creative environments. In another large-scale study in Germany, Freund and Holling (2008) conducted a statistical analysis of grade-point average (GPA) against indicators of creativity and reasoning ability for 1133 lower secondary-age pupils in 60 classes. They observed a strong effect for reasoning ability and, to a somewhat lesser degree, also for creativity when predicting GPA for individual pupils. Kendall et al. (2008a) conducted a national evaluation of the impact of Creative Partnerships (CP) in England, analysing achievement data from 398 core schools (primary \& secondary) in $16 \mathrm{CP}$ areas against national data. Although they observed no significant differences in attainment at Key Stage 2 (ages 7-11), at secondary level there was a measurable - if small - impact. For all four outcome measures considered (average Key Stage 3 score, English, mathematics and science), the progress of young people known to have taken part in CP in Key Stage 3 (ages 11-14) was statistically significantly greater than that of similar pupils nationally. At Key Stage 4 (ages 14-16), for four of the outcome measures considered (total GCSE point score, best 8 point score, English and science), the progress of young people known to have taken part in $\mathrm{CP}$ was statistically significantly greater than that of similar young people nationally. No difference was found however for young people's progress in mathematics at age 16.

Other smaller-scale studies have also noted achievement gains. For example, from a series of case studies in infant and primary schools, Grainger et al. (2005) observed a strong relationship between opportunities for creativity and pupil achievement. In an experimental study of four primary classrooms, two of which represented 'play-rich' environments, whilst 
the other two were 'controls' with formal, teacher-led pedagogy, Whitebread et al. (2009) noticed differences in the quality of pupils' written stories in response to a story which had been read to them. In the play condition classrooms, pupils' stories contained more conflicts and resolutions than the control group. Also, more of these were different from those in the original story which had been read to the children. Whitebread et al. (2009) concluded that pupils immersed in a play-rich (creative) environment generally wrote stories of higher quality than in a traditional 'taught' environment. In a report on Aspire Pilot, a National Endowment for Science, Technology and the Arts (NESTA)-funded initiative at the Open University, teachers in two 11-18 schools recognising increased quality in student work (Craft et al. 2008), particularly in the case of lower-achieving students.

\section{Confidence}

There is some evidence for increased levels of learner confidence associated with creative environments. Galton's ethnographic study of 11 creative practitioners working in six schools in three CPs noted a self-reported increase in self-confidence amongst primary-age pupils, particularly amongst those from disadvantaged schools. Similarly, a study of 19 Scottish schools implementing creative initiatives reported increases of pupil confidence and imagination across the age-range (LTS 2004). In their case studies of three primary teachers working in different parts of England, one in a culturally-diverse area of inner London, Cremin, et al. (2006) found that the creative environments created by teachers fostered pupils' sense of autonomy and intentionality, whilst Bancroft et al. (2008) observed an increasing confidence to tackle a range of material amongst children in the early years and primary phases of the $5 \times 5 \times 5=$ creativity project.

\section{Resilience}

Closely related to children and young people's confidence is their resilience as learners, observed by Bancroft et al.(2008) as an increased ability to deal with conflicts and difficulties, whilst remaining more relaxed and being prepared to persevere with challenging tasks they face. The primary-aged children in Galton's ethnographic study (2010) talked about their enhanced ability to face challenges, whilst the LTS (2004) study of Scottish schools reported more sustained engagement with tasks. For the children in the experimental comparison of play-based and 'taught' environments observed by Whitebread et al.(2009) 
there was a significant difference between the times children persevered with a task and the learning environment in which they had been immersed. Children in the play-based (creative) environment were prepared to spend longer on open tasks, whilst those in the control group experiencing a 'taught' environment spent longer on closed tasks. Jindal-Snape et al. (2011) suggest that involvement in games based projects enhanced children's resilience to change.

\section{Motivation and Engagement}

There is some evidence for increased levels of pupil motivation and engagement arising from creative environments (LTS 2004, Cremin et al.2006, Bancroft et al.2008, Craft et al.2008, Wood and Ashfield 2008). Secondary-age students in the Aspire Pilot project (Craft et al. 2008) were observed to be highly motivated and engaged in their work on the project, whilst creativity initiatives in Scottish schools were associated with increased levels of motivation, enthusiasm and enjoyment (LTS 2004). Wood and Ashfield's (2008) case study of five primary schools in Surrey using the interactive whiteboard (IWB) creatively found that participants frequently reported increases in pupils' concentration, motivation, attention and focus; whilst Cremin, et al. (2006) noted that the creative approaches of their three casestudy primary teachers had enhanced the children's involvement in tasks, a finding echoed in relation to the $5 \times 5 \times 5=$ creativity project (Bancroft et al.2008). In relation to the use of ICT, Jindal-Snape et al. (2011) found the use of games-based approaches to school transfer motivates young people to participate and to learn, reduces the generational gap, provides pupils an opportunity to contribute to the teaching-learning environment and act as an important part of the youth culture.

\section{Creative thinking and problem solving skills}

Perhaps unsurprisingly, there is evidence that some initiatives designed to enhance pupils' creativity achieved this objective. In a study of secondary biology teaching in 22 schools across New Zealand, involving 23 teachers and approximately 400 pupils, Haigh (2007) concluded that introducing open investigative practical work to biology programmes can enhance the creative thinking of students. In particular, being required to answer a number of 'What? How? How many? When? Where? and Why?' questions encouraged what Craft $(2001,2010)$ refers to as 'possibility thinking'. Webster et al.(2006) conducted an intervention study in three primary schools in Australia (236 children) in order to 
differentiate the conditions that support creative and analytical thinking. Teachers in the study identified a correlation between the duration of the incubation of ideas and the degree of creativity exhibited by students. The three primary teachers in the case-study by Cremin et al.(2006) enabled pupils to learn through asking questions and finding problems that they wished to solve, whilst Whitebread's (2007) experimental study contrasting play-rich environments with traditionally taught 'control' groups observed a significantly greater level of originality on open tasks when a play condition preceded the task. They concluded that playful experiences are effective in preparing children for effortful, problem solving or creative tasks (Whitebread 2007).

\section{Intrapersonal and interpersonal skills}

There is some evidence that creative learning environments can aid children and young people's emotional development and social skills (Matthews 2007, Whitebread et al.2007, Bancroft et al.2008, Galton 2010). Children in Matthews' (2007) study of a six-week creative arts intervention for primary-secondary transition in two classes of 10-11 year-old pupils in the same London school became more articulate about their concerns, reflective and emotionally aware. The creative process had allowed them to engage with their own identity, leading Matthews (2007) to conclude that the creativity is essential for children's emotional and psycho-social development. The results of an experimental study into play-rich environments (Whitebread et al.2007) suggest that play promotes self-regulation and metacognition. Bancroft et al.(2008) observed enhanced interpersonal skills in the children involved in the $5 \times 5 \times 5=$ creativity project, namely greater willingness to play and value each other's work as well as engaging in negotiation. Primary and secondary-age pupils in Galton's (2010) ethnographic study of 11 creative practitioners working in six schools talked about the transformative impact of CPs on their relationships with peers and teachers.

\section{Attendance}

There is evidence from only one study (Kendall et al.2008b) of any impact on pupil attendance. In their large-scale evaluation of the CP initiative, they found that, for primary schools, participation in $\mathrm{CP}$ was associated with a greater reduction over time in total absence rates than that in schools not engaged with CP. However, no significant associations between absence rates and participation in CP were found for secondary schools (Kendall et al.2008b). 
It is interesting to compare this finding with those from their study of pupil attainment (Kendall et al.2008a) in which the impact was only observed on secondary pupils and not on those in primary schools.

\section{Differences in impact related to gender, age, attainment level and socio-economic context}

Very few studies on creativity in education mention the characteristics of the pupils involved in the studies, so limited conclusions can be drawn as to any differential impact.

\section{Effect of gender}

Whilst there were no studies in our sample reporting a differential impact of creative environments on girls and boys, gender was a significant influence on children's creative performance in the large-scale study of primary schools in and around Paris (Besancon and Lubart 2008). In their study, girls showed better performance than boys on the three divergent tasks from the Torrance Tests of Creative Thinking and two integrative thinking tasks used to measure creativity. In Jindal-Snape et al. (2011) study, teachers reported that boys were more enthused by the computer game element of the Guitar Hero project (a commercial off the shelf game) whereas the girls were more enthused by drawing posters and publicity material, creating merchandise for the bands etc. However, during observations conducted by the researchers, children were equally engaged in all aspects.

\section{Effect of pupil age}

In Besancon and Lubart's 2-year study of 211 children in Paris and the surrounding areas (2008) children's performance on the creativity tests increased on average from grade 2 to grade 4 (ages 7 to 9) and stabilized or decreased in grade 5 (age 10).

\section{Effect of pupil attainment level}

In the evaluation of the Aspire Pilot (Craft et al. 2008) all pupils were highly motivated and engaged in the project work. Teachers commented that the lower-achieving secondary- 
age pupils were unusually highly motivated and engaged in their work with improvement in the quality of their work.

\section{Effect of pupil socioeconomic status}

The three studies reporting on pupil socioeconomic status (Jeffrey 2006, Schacter et al.2006, Galton 2010) produce some contrasting findings, possibly because they were set in different countries. Pupils across Europe in the Creative Learning and Student Perspectives (CLASP) research project "who had not benefited from an experience of individual study programmes or whose home environments were not conducive to study, found themselves alienated" (Jeffrey 2006, 405) from flexible classroom environments. In their observations of 48 teachers in US primary schools, Schacter et al.(2006) observed that classrooms with high proportions of minority and low performing students receive significantly less creative teaching. This was seen to be linked with teachers not being able to initiate, conduct and evaluate creativity, and their focus on standards and state assessments. In Galton's (2010) ethnographic study of CPs, pupils at the most disadvantaged school had the highest motivational and attitudinal scores and for self-esteem on average had 10 percentage points more than their peers at the other two primary schools. The staff in that school were seen to be working actively alongside creative partners.

\section{Conclusions}

The evidence from these 18 studies suggests impact from immersion in creative learning environments on learners' academic achievement; increased confidence and resilience; enhanced motivation and engagement; development of social, emotional and thinking skills; and improved school attendance. However, it is clear that there are very few studies that provide robust evidence regarding the impact of creativity on learners. There are further gaps when we consider the impact of creativity in the context of gender, age, socioeconomic status and pupils' attainment. We did not come across any study that specifically looked at impact in the context of ethnicity. With governments across the world investing in providing a creative learning environment and professionals' belief that creativity has a positive impact, this is a worryingly large gap in research literature. On the other hand, the studies that did investigate the impact, found good weight of evidence that would confirm that the government and professionals' belief are justified. 
We realise that despite our attempts at synthesising evidence from a range of eligible literature, there may be a number of limitations. The date or geographical criteria used for the search was finalised in partnership with the Scottish body Learning and Teaching Scotland (LTS). It is possible that our search may have excluded significant studies published before 2006 or in a country outside the scope of this review. However, we did consider previous reviews so this might not be an issue.

Although we located 210 pieces of literature, during the screening a number of studies had to be rejected. However, this was done after intensive discussions within the research team and with LTS. The relatively small number of studies used in the actual review reflects the lack of an empirical evidence base in the relatively 'soft' and hard-to-define area of creativity and education, with most being philosophical, anecdotal or polemical.

It is imperative that future research in conducted in this area, especially using research designs that capture baseline data to be able to demonstrate the impact clearly. Crosssectional and longitudinal studies should be undertaken to identify the impact across school years and ages. It is important to investigate the maintenance of this impact in the long term. Alongside this, it is important to capture the voices of the learners themselves, especially to understand why there is a positive impact. The findings from this review suggest that policy makers should make schools aware of impact of creativity on pupil attainment. This might give them confidence to promote creative learning environments that can support pupil achievement and well-being. Teachers also require appropriate training to enable them to facilitate a creative learning environment in their class.

Note: The authors would like to acknowledge the support of Learning and Teaching Scotland (LTS) in funding this research.

\section{References}

Bancroft, S., Fawcett, M. \& Hay, P. (2008) Researching children researching the world: $5 \times 5 \times 5=$ creativity. Stoke-on-Trent: Trentham. 
Besancon, M., \& Lubart, T. (2008) Differences in the development of creative competencies in children schooled in diverse learning environments. Learning \& Individual Differences, 18(4), 381-389.

Craft, A. (2001) Creativity in Education. Accessed on 12 $2^{\text {th }}$ April 2011 from http://www.euvonal.hu/images/creativity_report.pdf

Craft, A. (2010) Teaching for Possibility Thinking - what is it and how do we do it? Learning Matters, 15(1), 19-23

Craft, A., Chappell, K. \& Twining, P. (2008) Learners reconceptualising education: widening participation through creative engagement? Innovations in Education and Teaching International, 45(3), 235-245

Cremin, T., Burnard, P., \& Craft, A. (2006) Pedagogy and possibility thinking in the early years. Thinking Skills \& Creativity, 1(2), 108-119.

Davies, D., Jindal-Snape, D., Hay, P., Howe, A., Collier, C., \& Digby, R. (2011) Creative Environments for Learning in Schools: a systematic review of literature. Bath: Report for Learning and Teaching Scotland.

Davies, D., Jindal-Snape, D., Collier, C., Digby, R., Hay, P., \& Howe, A. (2012) Creative learning environments in education-A systematic literature review. Thinking Skills \& Creativity. Accessed on $5^{\text {th }}$ September 2012 from http://dx.doi.org/10.1016/j.tsc.2012.07.004

Dude, M. (2000) Architecture of schools: the new learning environments. London: Architectural Press.

Evidence for Policy and Practice Information and Co-ordinating Centre (EPPI-Centre) (2007) EPPI-Centre methods for conducting systematic reviews. London: EPPI-Centre, Social Science Research Unit, Institute of Education, University of London. 
Fraser, B. J., \& Fisher, D. L. (1982) Predicting students' outcomes from their perceptions of classroom psychosocial environments. American Educational Research Journal, 19, 498518.

Freund, P., \& Holling, H. (2008) Creativity in the Classroom: A Multilevel AnalysisInvestigating the Impact of Creativity and Reasoning Ability on GPA. Creativity Research Journal, 20(3), 309-318.

Galton, M. (2010) Going with the flow or back to normal? The impact of creative practitioners in schools and classrooms. Research Papers in Education, 25(4): 355-375.

Grainger, T., Goouch, K., \& Lambirth, A. (2005) Creativity and writing: developing voice and verve in the classroom. London: Routledge.

Haigh, M. (2007) Can Investigative Practical Work in High School Biology Foster Creativity? Research Science Education, 37, 123-140.

HMIE. (2006) Emerging good practice in promoting creativity. Retrieved on 22nd March 2011 http://www.hmie.gov.uk/documents/publication/hmieegpipc.html

Jeffrey, B. (2006) Creative teaching and learning: towards a common discourse and practice. Cambridge Journal of Education, 36(3), 399-414.

Jindal-Snape, D., Baird, L., \& Miller, K. (2011) A longitudinal study to investigate the effectiveness of the Guitar Hero project in supporting transition from P7-S1. Report for LTS. Dundee: University of Dundee.

Kendall, L., Morrison, J., Sharp, C., \& Yeshanew, T. (2008a) The longer-term impact of Creative Partnerships on the attainment of young people: Results from 2005 and 2006. Slough: National Foundation for Educational Research.

Kendall, L. Morrison, J. Sharp, C., \& Yeshanew, T. (2008b) The impact of Creative Partnerships on Pupil Behaviour. Accessed on $11^{\text {th }}$ April 2011 from http://www.nfer.ac.uk/nfer/publications/CPW01/CPW01.pdf 
LTS. (2004) Creativity Counts: A Report of Findings from Schools. Dundee: Learning and Teaching Scotland.

Matthews, L. (2007) Can the Process of Transition for Incoming Secondary Pupils be Supported through a Creative Art Project? International Journal of Art \& Design Education, 26(3), 336-344.

Mumford, M.D., Mobley, M.I., Uhlman, C.E., Reiter-Palmon, R., \& Doares, L.M. (1991) Process analytic models of creative thought. Creative Research Journal 4, 91-122.

Ofsted (2010). Learning: Creative approaches that raise standards. (HMI 080266).

Roth, M. (2000) Learning environments research, lifeworld analysis, and solidarity in practice. Learning Environments Research, 2, 225-247.

Schacter, J., Thum, Y., \& Zifkin, D. (2006) How Much Does Creative Teaching Enhance Elementary School Students' Achievement? Journal of Creative Behavior, 40(1), 47-72.

Torrance, E. P. (1977) Discovery and nurturance of giftedness in the culturally different. Reston, VA: Council on Exceptional Children.

Webster, A., \& Campbell, C. (2006) Enhancing the Creative Process for Learning in Primary Technology Education, International Journal of Technology and Design Education, 16, 221235.

Whitebread, D., Coltman, P., Jameson, H., \& Lander, R. (2009) Play, cognition and selfregulation: What exactly are children learning when they learn through play? Educational \& Child Psychology, 26(2), 40-52.

Williamson, P. K. (2011) The creative problem solving skills of arts and science studentsThe two cultures debate revisited. Thinking Skills \& Creativity, 6(1): 31-43. 
Wood, R., \& Ashfield, J. (2008) The use of the interactive whiteboard for creative teaching and learning in literacy and mathematics: a case study. British Journal of Educational Technology, 39(1), 84-96. 


\section{Box 1: Creative learning environments and activities}

The literature reviewed focussed on creative learning environment with some examples of activities that promoted creativity.

\section{Creative learning environment:}

\section{a) The physical environment}

The research suggested that the structuring of the physical environment had an impact on learners. The main features included flexible use of space; flexibility and free movement around the space; using different areas within the class room; providing a wide range of appropriate materials, tools and other resources (clay, wire, cellophane, games, whiteboard, computer games, etc.); and working in an outdoor environment such as museums and galleries. Forest schools provided an example of good physical environment.

\section{b) The pedagogical environment}

The research suggested that to enhance creativity, learners should be given some control over their learning and supported to take risks with the right balance between structure and freedom. Teachers should bring more 'playful' or 'games-based' approaches into classrooms at all stages; use the time in a flexible manner; allow pupils to work at their own pace; build a good relationship with the learners based on high expectations, mutual respect, modelling of creative attitudes, flexibility and dialogue; and provide learners' opportunities for working collaboratively with their peers.

\section{c) The role of partnerships beyond the school}

Research suggested that collaboration and involvement with outside agencies, including the local business community, the wider sporting and Arts community, and other community organisations can be a significant feature of a creative environment. For example, Jeffrey (2006), observed that 'critical' creative events usually involved collaboration with dancers, artists, sculptors, actors and environmental workers. Similarly, in We're Writers project, Grainger et al. (2005) note the importance of links 
with the wider community in relation to the development of children's poetry writing.

\section{Activities to promote creativity:}

Reviewed literature included a range of activities that could promote creativity, namely, experimentation with new media technologies; ICT resources such as the interactive whiteboard and computer games; brainstorming; mind mapping; listening to music during activities; drawing; role playing and drama; stories; music; fantasy play; outdoor play; expressive painting; model making; expressive and imaginative movement; planting a garden; building a den; designing a piece of play equipment; making of memory boxes; practical work for example related to science.

\section{Box 2: Summary of good practice in promoting creativity in Scottish schools}

A survey of evidence from inspections of pre-school centres, primary and secondary schools, and community learning and development (CLD) in Scotland by HMIE (2006) synthesised the following elements of good practice in promoting creativity:

- Learners were able to respond more creatively when they had a positive relationship with teachers and peers, and teachers encouraged them to learn from their mistakes, ask questions and express their individual ideas.

- Learners were seen to live up to the expectations of their teachers when the environment and activities were designed to promote creativity, and the teachers expected the learners to take risks, give diverse responses, express themselves and persevere.

- The quality of learners' response was improved when teachers provided thought provoking stimuli and asked challenging questions, but withdrew when appropriate.

- Staff in nurseries routinely used different activities to promote children's creativity. These included role play, music, painting, model making, and expressive and imaginative movement.

- Indoor and outdoor activity areas were seen to be successful in promoting imaginative and exploratory play.

- Creativity in science was best developed through open-ended investigations requiring 


critical and analytical skills which could be combined with the learners' existing
knowledge and experience, to hypothesise, test and re-test if required.
CLD providers used creative arts, such as drama and music, to engage with young
people and to provide opportunities for empowerment.

\section{Box 3: Summary of good practice in promoting creativity in English nurseries, primary and secondary schools}

OfSTED (2010) in a survey of inspection findings from 44 schools (two nursery schools, 22 primary schools, 19 secondary schools and a special school), identified the following characteristics of effective creative teaching:

- Teachers guided but did not over-direct learners.

- Teachers emphasised developing skills such as problem-solving and communication, and the learners were able to understand their progress and how it took them to the next level of competence.

- Teachers' skills in questioning learners were excellent and they encouraged learners to be inquiry-minded and to look for multiple possibilities.

- Learners with a range of abilities and interests were fully engaged and appropriately challenged.

- Teachers and learners used many kinds of technology effectively. A whole-school approach to developing and using technology is required to enhance learners' confidence and engagement.

- Teachers used role play effectively for exploration of ideas, development of empathy and team working, and to build learners' confidence.

- Teachers and learners engaged positively with external partners and made most of the creative opportunities provided. Those partnerships that complemented schools' mainstream curriculum made a significant contribution to learning and personal development.

- Good professional development within the school was essential for supporting teachers to use creative approaches and to improve their subject knowledge. Without that, externally produced training or short courses were meaningless.

- Teachers allowed learners' independence as creative learners but did not let it lessen the rigour of the work. 
